\title{
Effect of biomass features on oxygen transfer in Conventional Activated Sludge and Membrane BioReactor systems
}

Marco Capodicia, Santo Fabio Corsino ${ }^{a}$, Daniele Di Trapani, ${ }^{a}$, , Michele Torregrossa ${ }^{\mathrm{a}}$, Gaspare Viviani $^{\mathrm{a}}$

${ }^{a}$ Department of Engineering, University of Palermo, Viale delle Scienze Ed. 8, 90128 Palermo, ITALY

*Corresponding author: Daniele Di Trapani E-mail address: daniele.ditrapani@unipa.it Phone: +39 09123896552

\section{Abstract}

The aim of the present study was to compare the oxygen transfer efficiency in a conventional activated sludge and a membrane bioreactor system. The oxygen transfer was evaluated by means of the oxygen transfer coefficient $\left(\mathrm{k}_{\mathrm{La}}\right)_{20}$ and $\alpha$-factor calculation, under different total suspended solids concentration, extracellular polymeric substances, sludge viscosity and size of the flocs. The $\left(\mathrm{k}_{\mathrm{L} a}\right)_{20}$ and $\alpha$-factor showed an exponential decreasing trend with total suspended solid, with a stronger $\left(\mathrm{k}_{\mathrm{L}}\right)_{20}$ dependence in the conventional activated sludge than the membrane bioreactor. It was noted that the $\left(\mathrm{k}_{\mathrm{L}}\right)_{20}$ in the conventional activated sludge become comparable to that in membrane bioreactor when the TSS concentration in the conventional activated sludge was higher than 5 gTSS $\mathrm{L}^{-1}$. Operating under high carbon to nitrogen ratio, the $\left(\mathrm{k}_{\mathrm{L}} \mathrm{a}\right)_{20}$ increased in both conventional activated sludge and membrane bioreactor because of the sludge deflocculation and a weaker dependence of $\left(\mathrm{k}_{\mathrm{L}} \mathrm{a}\right)_{20}$ with total suspended solid was noted.

The results indicated that the most important parameters on the oxygen transfer efficiency were in order: the total suspended solid concentration, flocs size, sludge viscosity, the protein to polysaccharides ratio and extracellular polymeric substances content. Based on the influence of the main biomass features affecting the $\left(\mathrm{k}_{\mathrm{L}} \mathrm{a}\right)_{20}$ and considering the typical operating conditions in both systems, those of membrane bioreactor appeared to be more favorable to oxygen transfer efficiency compared to conventional activated sludge process.

Keywords: Aeration efficiency, activated sludge properties, EPS, Membrane Bioreactor, Oxygen transfer; Energy consumption 


\section{Introduction}

36 Energy saving has become one of the most debated topic in the field of any industrial activity, including also wastewater treatment plants (WWTP) (Henriques and Catarino, 2017; Torregrossa et al., 2018). Aeration is the most energy-intensive operation in wastewater treatment, amounting to 4575\% of plant energy costs (Rosso et al., 2008; Li et al., 2017; Wu et al., 2019); this operation is crucial in WWTPs, since dissolved oxygen (DO) represents an essential factor in biological processes for the treatment of both municipal and industrial wastewater (Tang et al., 2015).

Over recent years, several aeration machineries manufactories have developed innovative devices with the aim to increase the aeration efficiency in terms of mass of oxygen transferred per unit energy required (Zheng et al., 2018). In parallel, the plant facilities were upgraded by equipping those machineries that are more efficient in order to maximize the amount of oxygen that transfers from air to water (Hewawasam et al., 2017). Nevertheless, oxygen transfer process does not depend entirely on diffusers or aerators design, but also on the biomass characteristics (Germain and Stephenson, 2005). Indeed, several investigations have linked the limitation to the oxygen transfer to solids concentrations and viscosity of mixed liquor, as well as the content of soluble microbial products (SMP) and extracellular polymeric substances (EPS) (Germain et al., 2007). Therefore, a better understanding of the energy saving strategies requires deeper investigations on the oxygen transfer phenomena in relation with biomass characteristics.

Whilst on the one hand the energy-saving necessity led operators and manufactories to implement strategies and devices with low environmental impact, on the other, the more stringent environmental laws has driven researchers toward advanced technologies that are more energy-consuming (Krzeminski et al., 2012). Among these, the membrane bioreactors (MBRs) technology is largely considered the first alternative to the conventional activated sludge (CAS) process because of the higher effluent quality, compatible with the water reuse requirements, and the lower footprint (Hoinkis et al., 2012). Nonetheless, in MBR the main power requirement comes from aeration, which 
60 is used for oxygen supply and membrane scouring to prevent fouling formation (Germain et al.,

61 2007). Therefore, the improvement of aeration design with a reduction of the energy consumption is of great importance to push the widespread application of MBRs (Xu et al., 2017). In MBR systems, the biomass features may differ significantly from that of CAS plants, including the higher viscosity and EPS content, the smaller particle size, etc. (Di Bella et al., 2010). Similarly, some operating parameters, like the hydraulic retention time (HRT), the solid retention time (SRT), the food to microorganisms ratio $(\mathrm{F} / \mathrm{M})$, might be significantly different to that of CAS (Bertanza et al., 2017). All these factors highly affect the oxygen transfer efficiency, which is usually expressed in terms of global oxygen transfer coefficient $\left(\mathrm{k}_{\mathrm{L}} \mathrm{a}\right)$; moreover, the alpha-factor $(\alpha$-factor), defined as the ratio of $k_{\mathrm{L}}$ under process and clean water conditions, accounts for the effects of activated sludge features (Verrecht, 2010). Some of the above parameters are known to be associated with lower oxygen transfer efficiency, as TSS concentration, viscosity and EPS content, whereas others, like particle size, HRT and F/M, are favorable to oxygen transfer (Germain et al., 2007). The main detail, the study was aimed at assessing: the different contribution to oxygen transfer efficiency, make difficult the possibility to assess a comprehensive analysis on aeration efficiency by default. In several studies, it was speculated that the main factor affecting the difference between oxygen transfer in CAS and MBR systems is the flocs size (Fan et al., 2017). For this reason, because the mass transfer is linked to the contact area between gas and liquid phase, the MBR should be favored because of the smaller particles size (Germain et al., 2007). Nevertheless, a comparison between the impact of the particles size on the oxygen transfer efficiency in CAS and MBR was not investigated so far and, in general, very limited data of $\mathrm{k}_{\mathrm{La}}$ and $\alpha$-factor for MBRs have been reported (Xu et al., 2017).

In this light, the aim of this study was to analyze the oxygen transfer in CAS and MBR systems. In detail, the study was aimed at assessing: 
2) the impact of the activated sludge flocs size on the oxygen transfer efficiency in CAS and MBR;

3) the influence of the main biomass features on the $\mathrm{k}_{\mathrm{L}} \mathrm{a}$.

\section{Material and methods}

\subsection{CAS and MBR plant configuration}

As aforementioned, in the present study two bench scale plants, one CAS and one MBR, were startedup to study the oxygen transfer efficiency. The CAS plant consisted in one aerobic reactor $(25 \mathrm{~L}$ of volume) and a clarifier (3 $\mathrm{L}$ of volume, $7.84 \cdot 10^{-3} \mathrm{~m}^{2}$ of surface). The MBR was realized according to the submerged side-stream configuration, consisting in one aerobic reactor ( $24.5 \mathrm{~L}$ of volume) and another one (2.5 L of volume) where an ultra-filtration (UF) hollow fibers (HF) membrane module $\left(\right.$ Zee-Weed ${ }^{\circledR}$, specific area $=0.1 \mathrm{~m}^{2}$ and nominal porosity $=0.04 \mu \mathrm{m}$, courtesy of GE, $)$ was placed. The aerobic reactors of both the CAS and MBR were geometrically identical ( $\mathrm{L} \times 1 \times \mathrm{h}=0.35 \mathrm{~m} \mathrm{x}$ $0.35 \mathrm{~m} \times 0.20 \mathrm{~m}$ ) and were equipped with two equal fine bubble air diffusers each, for dissolved oxygen supply. The airflow rate was maintained constant at $6 \mathrm{~L} \mathrm{~min}^{-1}$. Fibers scouring was achieved by supplying air to the membrane, in order to mitigate the fouling formation. Both the systems were fed with a synthetic medium with a flow rate of $1 \mathrm{~L} \mathrm{~h}^{-1}$, resulting in a HRT of approximately $25 \mathrm{~h}$. The synthetic wastewater was stored into a continuously mixed tank from which it was fed through two peristaltic pumps to the aerobic reactors of the CAS and MBR systems. In the CAS, the activated sludge from the bottom of the clarifier was recycled to the aerobic reactor with a flow rate of $2 \mathrm{~L} \mathrm{~h}^{-1}$, whereas in the MBR the retentate from the membrane compartment was recycled to the aerobic reactor with a flow rate of $6 \mathrm{~L} \mathrm{~h}^{-1}$. The permeate flux was kept almost to $18 \mathrm{~L} \mathrm{~m}^{-2} \mathrm{~h}^{-1}$, while the net effluent flow rate was equal to $1 \mathrm{~L} \mathrm{~h}^{-1}$. The membrane filtration cycle was divided into

1085 min of filtration and 1 min of backwashing, by pumping back a small volume of permeate through the membrane. 
110 A schematic layout of the CAS and MBR systems is depicted in Figure 1.

111

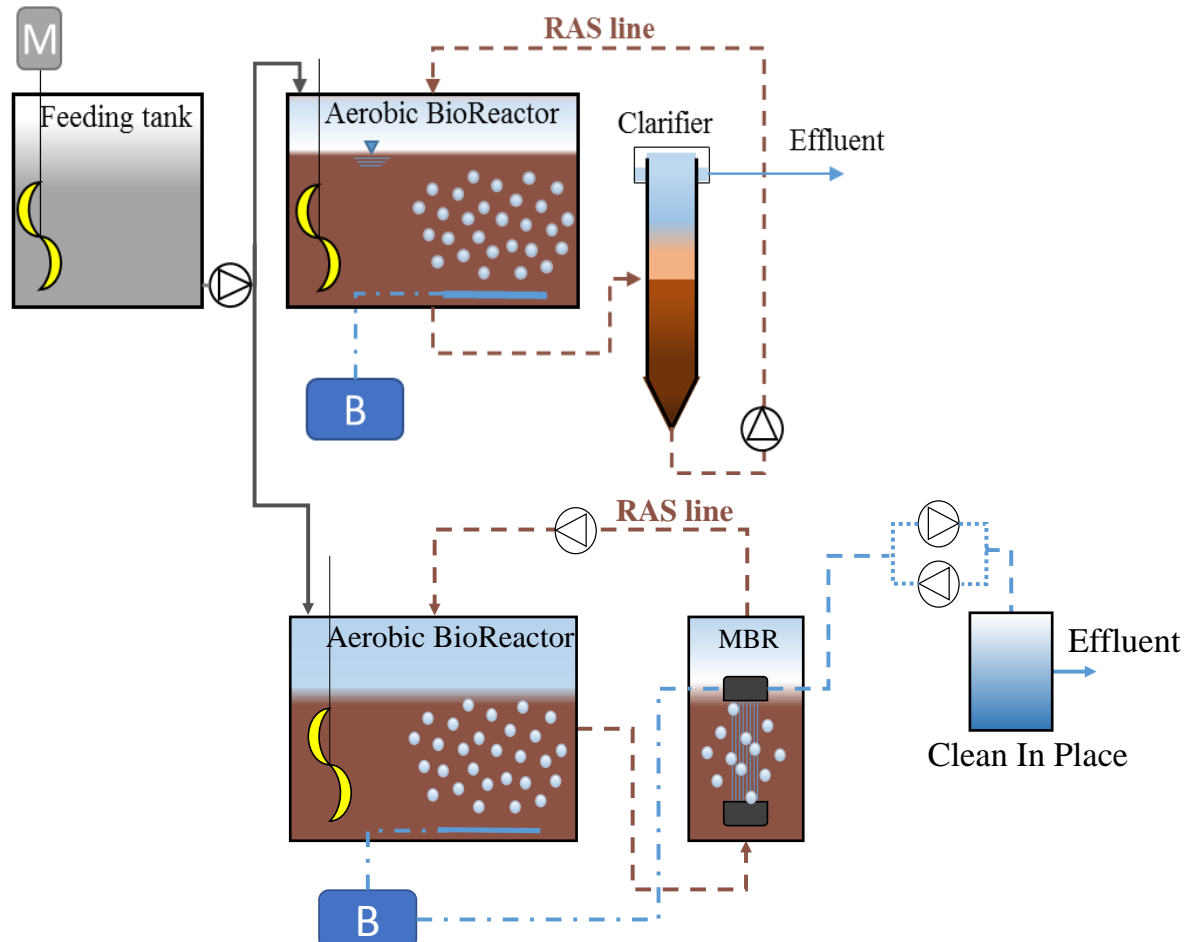

112

\section{$113 \quad 2.2$ Experimental campaign}

114 The experimental campaign had a duration of 70 days and it was divided into two different periods,

115 named Period 1 and Period 2. During Period 1 (50 days), the CAS and MBR were fed with a synthetic

116 wastewater having a C/N/P ratio of approximately 100:10:2. During Period 2 (20 days), the amount

117 of nitrogen and phosphorous in the synthetic medium was decreased, resulting in a C/N/P ratio of

118 100:2.5:0.5, in order to favour the activated sludge deflocculation in the CAS because of unbalanced

119 nutrients condition. The main features of the synthetic wastewater are reported in Table 1.

120

\begin{tabular}{lccc}
\hline Parameter & Unit & Period 1 & Period 2 \\
\hline COD (as sodium acetate) & $\mathrm{mg} \mathrm{L}^{-1}$ & $382.8 \pm 20.1$ & $392.4 \pm 26.3$ \\
$\mathrm{NH}_{4}-\mathrm{N}$ (as ammonium chloride) & $\mathrm{mg} \mathrm{L}^{-1}$ & $37.8 \pm 3.9$ & $18.9 \pm 3.2$ \\
$\mathrm{PO}_{4}-\mathrm{P}$ (as hydrogen potassium phosphate) & $\mathrm{mg} \mathrm{L}^{-1}$ & $7.9 \pm 1.2$ & $3.8 \pm 0.7$ \\
$\mathrm{C}: \mathrm{N}: \mathrm{P}$ & - & $100: 10: 2$ & $100: 2.5: 0.5$ \\
\hline
\end{tabular}


Both plants were seeded with conventional activated sludge collected from the aeration tank of the

123 “Acqua dei Corsari” wastewater treatment plant located in Palermo (Italy), with initial concentrations of $3 \mathrm{gTSS} \mathrm{L}^{-1}$ and $6 \mathrm{gTSS} \mathrm{L}^{-1}$ for CAS and MBR, respectively.

\subsection{Determination of the oxygen transfer coefficient}

127 The oxygen transfer coefficient $\left(\mathrm{k}_{\mathrm{L}} \mathrm{a}\right)$ was evaluated within the same aerobic reactors, first with tap 128 water (before the inoculum) in order to calculate the $\left(\mathrm{k}_{\mathrm{L}} \mathrm{a}\right)$ referred to clean water conditions, then 129 with the biomass at different TSS concentrations. All the tests were performed in batch conditions 130 and at room temperature according to the non-steady-state batch test (Stenstrom et al., 2006). Before 131 starting the oxygen transfer measurement, the dissolved oxygen in water was removed. More 132 precisely, in the test with tap water a chemical oxygen demand (sodium sulphite and cobalt chloride 133 as catalyst) was added to the water, whereas in the test with biomass deoxygenation was achieved 134 because of the oxygen consumption by bacteria. The air blower was then switched on and, after a 135 while, the dissolved oxygen concentration reached the saturation value due to the aeration 136 (reoxygenation phase) at an airflow rate of $6 \mathrm{~L} \mathrm{~min}$. The dissolved oxygen concentration was 137 measured through an oxygen probe (WTW CellOX-325) coupled to an oximeter (WTW 138 MULTI340i).

139 The standard model for evaluating oxygen transfer is given by Equation 1.

$$
\frac{d C}{d t}=k_{L} a \cdot\left(C_{S}-C_{0}\right)
$$

141 where:

- $\mathrm{C}=$ dissolved oxygen concentration $(\mathrm{mg} / \mathrm{L})$;

$143 \quad-\mathrm{t}=$ time $(\min )$

144 - $\mathrm{k}_{\mathrm{L}} \mathrm{a}=$ volumetric mass transfer coefficient $\left(\mathrm{min}^{-1}\right)$;

145 - $\mathrm{C}_{\mathrm{S}}=$ dissolved oxygen saturation concentration at steady state $\left(\mathrm{mg} \mathrm{L}^{-1}\right)$;

146 - $\mathrm{C}_{0}=$ dissolved oxygen concentration at time zero $\left(\mathrm{mg} \mathrm{L}^{-1}\right)$. 
147 The equation used for data analysis with nonlinear regression is given in Equation 2 and is a derivation 148 from Equation 1:

$$
C=C_{S}-\left(C_{S}-C_{0}\right) \cdot e^{\left(-k_{L} a \cdot t\right)}
$$

By plotting the $\mathrm{C}$ values achieved during the reoxygenation phase in a graph $\ln \left(C_{S^{-}} C\right) /\left(C_{S^{-}} C_{0}\right)$ vs $t$, the volumetric mass transfer coefficient was obtained as the slope of the regression line. The $\mathrm{k}_{\mathrm{L}}$ a was then referred at the temperature of $20^{\circ} \mathrm{C}$ by using the equation 3 :

$$
\left(k_{L} a\right)_{20}=\left(k_{L} a\right)_{T} \cdot 1.024^{T-20}
$$

The $\alpha$-factor was obtained as the ratio of process to clean water conditions, as follows (eq. 4):

$$
\alpha=\frac{\left(k_{L} a\right)_{\text {process,water }}}{\left(k_{L} a\right)_{\text {clean,water }}}
$$

The oxygen transfer coefficient was periodically measured within the aerobic reactors of both CAS and MBR plants at different TSS concentrations, by concentrating or diluting the biomass samples.

\subsection{Analytical methods}

160 Extracellular polymeric substances extraction was carried out in accordance with the Heating Method

161 (Le-Clech et al., 2006). Therefore, for both the extracted SMP and EPS fractions, the carbohydrate and protein concentrations were determined according to the phenol-sulphuric acid method with glucose as the standard (DuBois et al., 1956) and by the Folin method with bovine serum albumin as the standard (Lowry et al., 1951), respectively.

The particle size distribution of both the activated sludge from CAS and MBR was measured by means of a high-speed image analyses sensor (Sympatec Qicpic) that provided the particle size distribution and the granulometric curve. The average size of the activated sludge flocs was calculated as the diameter of the particles corresponding to the $50 \%$ of the granulometric distribution. The morphology of the activated sludge flocs was evaluated with microscopic image observations performed by a phase contrast microscope (BX-53-Olympus). 
171 Microscopic observations were performed under phase contrast at 100× and 1000× magnifications.

172 The filamentous microorganisms were morphologically identified using the Eikelboom classification 173 system. Filamentous microorganism abundance and dominance were estimated according to the 174 literature (Jenkins et al., 2004).

175 The activated sludge viscosity was evaluated by means of a rotational rheometer (Brookfield digital 176 viscometer, model DV-E) equipped with concentric cylinders and an adapter for low viscosity at 177 constant temperature $\left(20^{\circ} \mathrm{C}\right)$.

\subsection{Statistical analysis}

180 In order to evaluate the influence of the main biomass features (TSS concentration, EPS content and 181 composition, sludge viscosity and size of the flocs) on the oxygen transfer coefficient, the multiple 182 regression analysis was performed. More precisely, the dependent variable was the oxygen transfer 183 coefficient, whereas the independent variables were the biomass features. The regression coefficients 184 (Beta coefficients) was used to evaluate the degree of influence of each biomass feature on the $\left(\mathrm{k}_{\mathrm{L}} \mathrm{a}\right)_{20}$, 185 according to the literature (Germain et al., 2007).

\section{Results and discussion}

\subsection{Features of the activated sludge in the CAS and MBR}

189 The main features of the activated sludge in the CAS and MBR in Period 1 and Period 2, in terms of EPS content and composition, flocs size and morphology, are shown in Figure 2. 


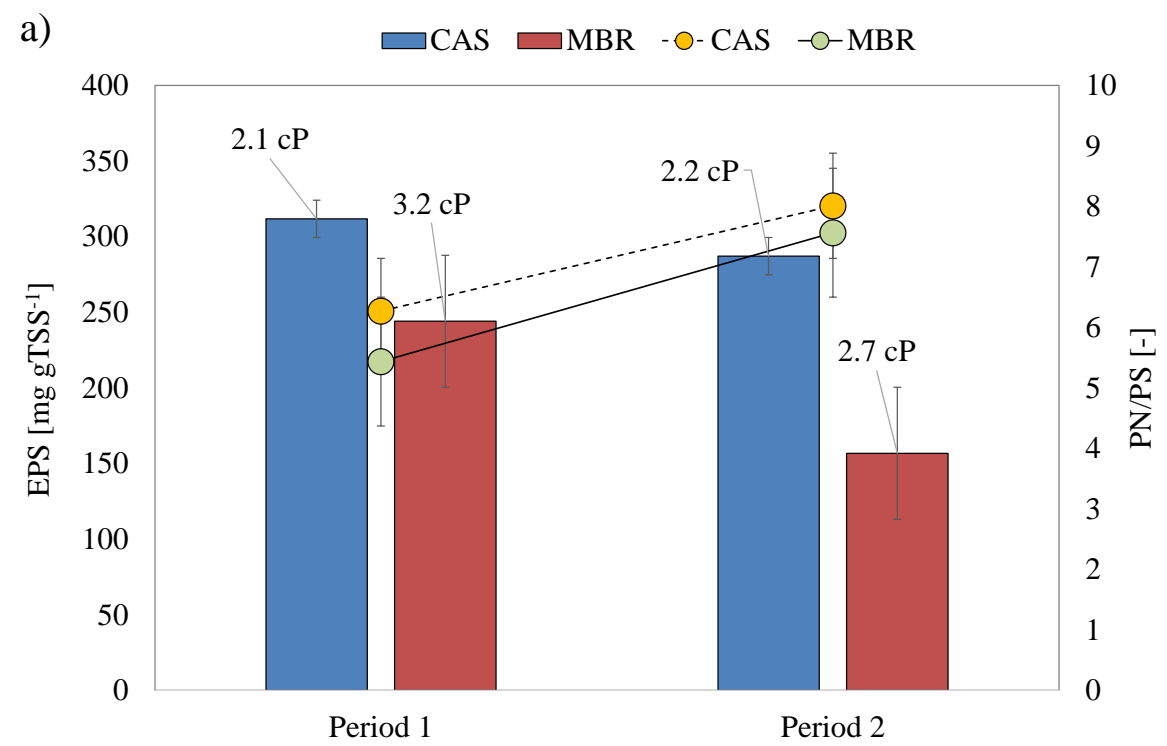

b)

Period 1

Period 2
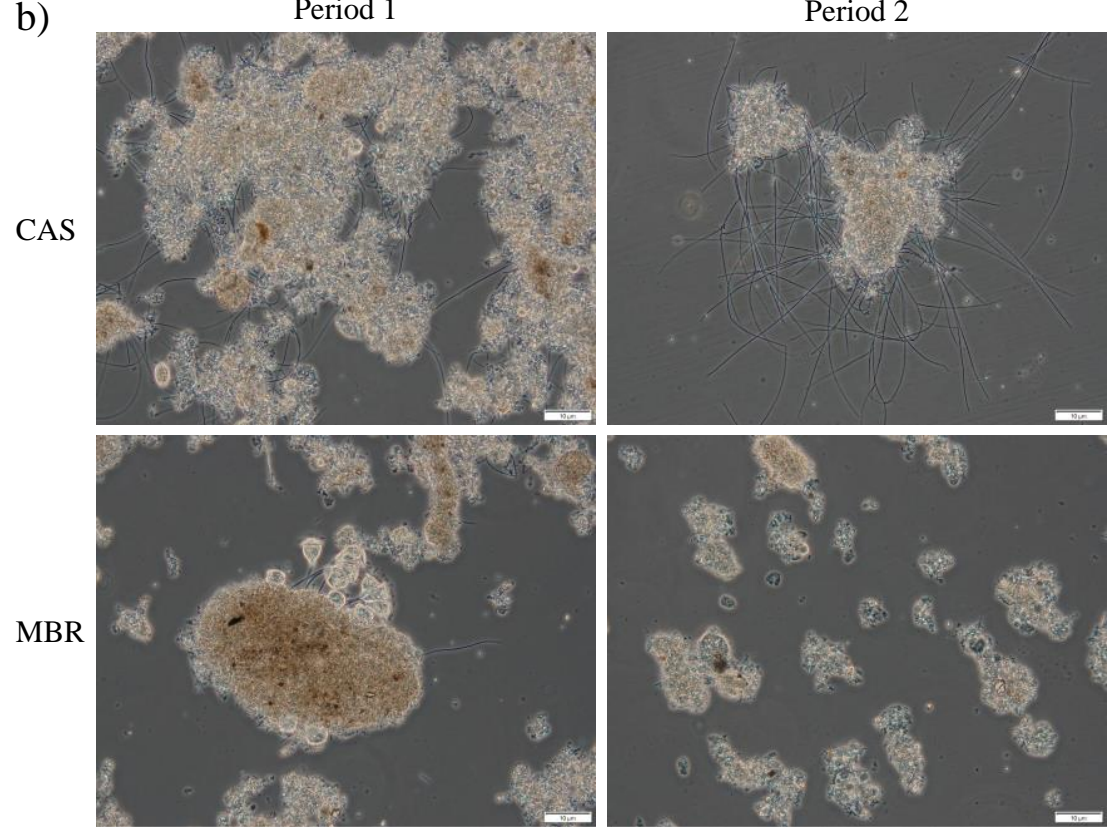

The average EPS content of CAS was of approximately $311 \mathrm{mg} \mathrm{g}^{-1} \mathrm{TSS}$ in Period 1, whereas it slightly decreased to $287 \mathrm{mg} \mathrm{g}^{-1}$ TSS in Period 2. Similarly, the EPS content of MBR decreased from $244 \mathrm{mg}$ $\mathrm{g}^{-1}$ TSS to $156 \mathrm{mg} \mathrm{g}^{-1}$ TSS from Period 1 to Period 2, indicating that the nutrient unbalance determined

197 a decrease in the EPS secretion by bacteria in both systems. The EPS composition changed as well 198 from Period 1 to Period 2. More precisely, the protein (PN) to carbohydrate (PS) ratio (PN/PS) 199 increased from 6.2 to 8 and from 5.4 to 7.5 in the CAS and MBR, respectively. Therefore, the nutrient 200 unbalance caused a simultaneous decrease in the amount of the total EPS and the enrichment in the 201 proteinaceous fraction of the extracellular polymeric matrix. 
202 The activated sludge viscosity did not change significantly from Period 1 to Period 2 in the CAS (2.1

$203 \mathrm{cP}$ vs $2.2 \mathrm{cP})$, whereas it slightly decreased in the MBR (3.2 cP vs $2.7 \mathrm{cP})$.

204 The morphology of the activated sludge flocs significantly changed from Period 1 to Period 2. Indeed, 205 in Period 1 the flocs were slightly irregular but compact in the CAS (average size of $91.8 \mu \mathrm{m}$ ), with 206 a common presence of filamentous bacteria (Nocardia sp, Microthrix Parvicella and Type 0675). In 207 Period 2, the activated sludge morphology changed to open-flocs structure (average size of $25.1 \mu \mathrm{m}$ ) 208 with a predominance of filamentous bacteria like Type 021N, Type 0965 and Thiotrix sp. In the MBR, 209 the activated sludge flocs were very small but with a regular and compact shape. The size of the flocs 210 was close to $27 \mu \mathrm{m}$ on average in Period 1 because of the deflocculation effect exerted by the 211 membrane. In Period 2, average size of the activated sludge flocs further decreased to approximately $21212 \mu \mathrm{m}$, whereas no significant changes in the morphology was observed. Filamentous bacteria like 213 Type 021N, Type 0965 and Thiotrix sp, were found dominant even in the MBR, although their effect 214 on the flocs morphology was marginal compared to that in the CAS.

\subsection{Oxygen transfer coefficient in the CAS and MBR: Period 1}

217 Biomass with TSS concentrations ranging from $1.5 \mathrm{gTSS} \mathrm{L}^{-1}$ and $5.3 \mathrm{gTSS} \mathrm{L}^{-1}$ and from $4.2 \mathrm{gTSS} \mathrm{L}^{-}$ $218{ }^{1}$ and 7.8 gTSS L $^{-1}$ were examined in the CAS and MBR, respectively, during Period 1 . The oxygen 219 transfer coefficient and the $\alpha$-factor obtained in the CAS and MBR at different TSS concentration in 220 Period 1 are depicted in Figure 3. 

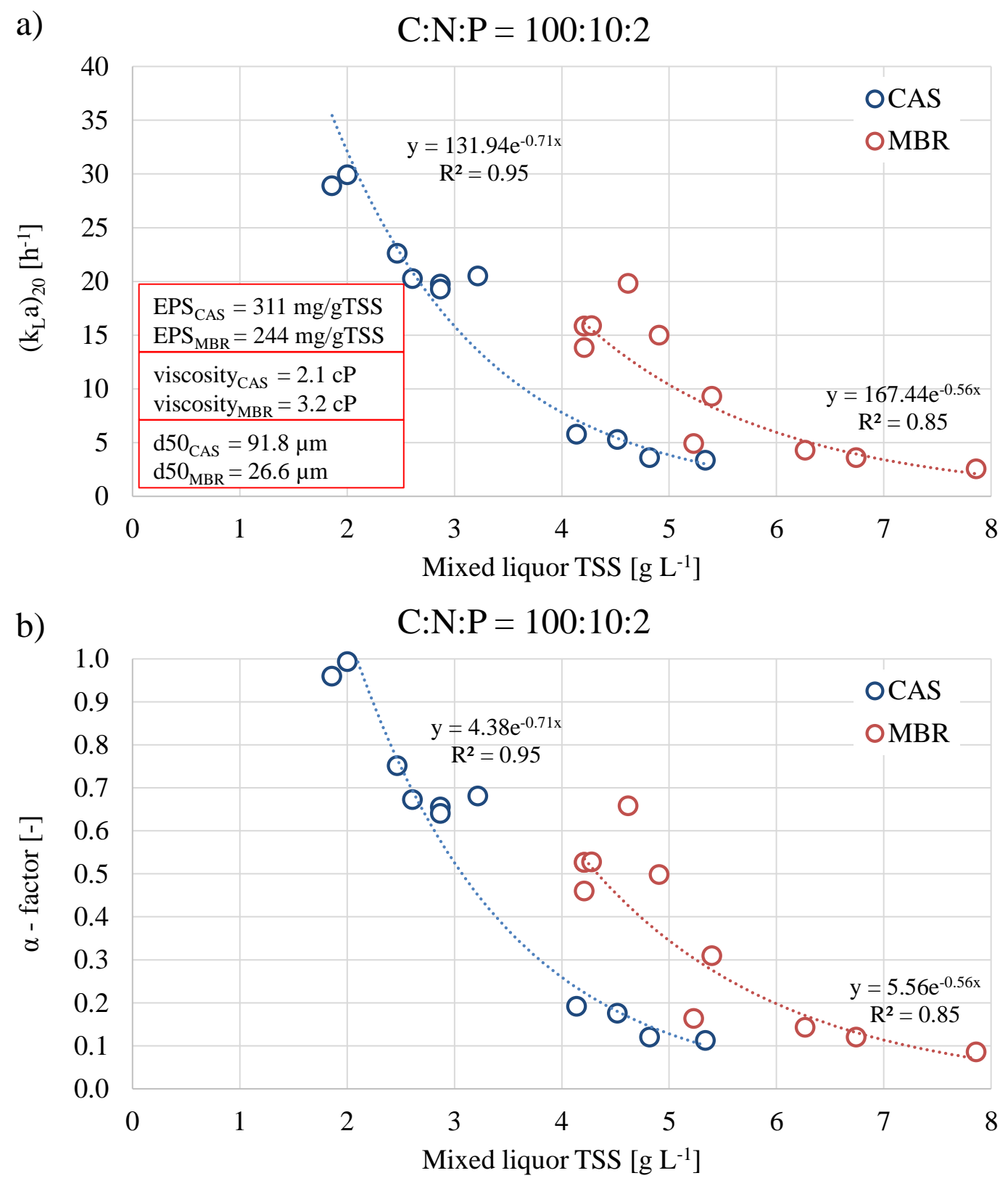

223 The $\left(\mathrm{k}_{\mathrm{L}} \mathrm{a}\right)_{20}$ coefficient showed and exponential decrease with the increase in TSS in both the CAS and MBR (Fig. 3a), in good agreement with previous findings (Wu et al., 2019). In general, the ( $\left.\mathrm{k}_{\mathrm{L}}\right)_{20}$ 225 values obtained by $\mathrm{Wu}$ and co-workers were slight lower compared to what achieved in the present 226 study for a similar TSS concentration range. These variations could be likely due to different testing conditions (e.g. aeration intensity, diffuser typology, reactor geometrical features, mixed intensity, etc.). The $\left(\mathrm{k}_{\mathrm{L} a}\right)_{20}$ decreased sharply from $30 \mathrm{~h}^{-1}$ to less than $5 \mathrm{~h}^{-1}$ when the TSS concentration increased from 2 gTSS L ${ }^{-1}$ to $4 \mathrm{gTSS} \mathrm{L}^{-1}$ in the CAS, whereas further increases in TSS did not 230 produced significant decrease in $\left(k_{L} a\right)_{20}$. Similarly, the $\left(k_{L} a\right)_{20}$ coefficient in the MBR decreased from 
231 approximately $16 \mathrm{~h}^{-1}$ to $4 \mathrm{~h}^{-1}$ when the TSS concentration increased from 4 gTSS L $\mathrm{g}^{-1}$ to $8 \mathrm{gTSS} \mathrm{L}^{-1}$.

232 The $\alpha$-factor (Fig. 3b) was of approximately 0.96 in the CAS at 2 gTSS L $^{-1}$, whereas it significantly 233 decreased in the range between $3 \mathrm{gTSS} \mathrm{L}^{-1}$ and $4 \mathrm{gTSS} \mathrm{L}^{-1}$ standing at a steady value of approximately 2340.15 . In the MBR the maximum values of the $\alpha$-factor were observed at $4 \operatorname{gTSS~L}^{-1}(\alpha=0.5)$, whereas 235 it decreased to less than 0.1 at TSS concentrations higher than $7 \mathrm{gTSS} \mathrm{L}^{-1}$.

236 By comparing the exponential decreasing trends observed in the CAS and MBR, it was noted that the 237 dependence of $\left(\mathrm{k}_{\mathrm{La}}\right)_{20}$ on TSS was stronger in the CAS than the MBR. Under the typical operating 238 TSS concentration in CAS $\left(3\right.$ gTSS L $\left.^{-1}\right)$ and MBR $\left(8\right.$ gTSS L L $\left.^{-1}\right)$, the obtained results confirmed that 239 oxygen transfer coefficient was lower in the MBR $\left(3.6 \mathrm{~h}^{-1} v s 20 \mathrm{~h}^{-1}\right)$. Nevertheless, it is worth noting 240 that the $\left(\mathrm{k}_{\mathrm{L}} \mathrm{a}\right)_{20}$ values in the CAS become comparable with that in MBR when the TSS concentration 241 in the CAS was higher than 5 gTSS L$^{-1}$, which is typical of plants operating under extended aeration. 242 Within a range of TSS between $4 \mathrm{gTSS} \mathrm{L}^{-1}$ and $6 \mathrm{gTSS} \mathrm{L}^{-1}$ the $\left(\mathrm{k}_{\mathrm{L}} \mathrm{a}\right)_{20}$ value resulted significantly 243 higher in the MBR, thereby suggesting that under similar operating conditions the features of the 244 activated sludge features in the MBR were more favorable to oxygen transfer.

245 Differences between the activated sludge features in the CAS and MBR were observed in terms of 246 EPS content and average size of the flocs. Indeed, although the mixed liquor viscosity was higher in 247 the MBR on average, the specific EPS content was higher in the CAS (311 $\mathrm{mg} \mathrm{g}^{-1} \mathrm{TSS}$ vs $244 \mathrm{mg} \mathrm{g}^{-}$ $248{ }^{1}$ TSS), as well as the average size of the activated sludge flocs, which resulted approximately equal 249 to $92 \mu \mathrm{m}$ and $27 \mu \mathrm{m}$ in the CAS and MBR, respectively. The above results suggested that the oxygen 250 transfer coefficient and the $\alpha$-factor, in addition to TSS concentration, strictly depend on the EPS 251 content and size of the activated sludge flocs. These results are in good agreement with the literature, 252 in which the negative effect of the EPS on $\left(\mathrm{k}_{\mathrm{L}} \mathrm{a}\right)_{20}$ was previously observed by several researchers 253 (Mueller et al., 2002; Germain et al., 2007).

254 It is reasonable to speculate that the decrease of $\left(\mathrm{k}_{\mathrm{L}} \mathrm{a}\right)_{20}$ in the MBR, due to the increase of TSS concentration, was compensated by the lower EPS content and the smaller size of the activated sludge 
flocs. Therefore, the latter might be the reason of the weaker relationship of the $\left(\mathrm{k}_{\mathrm{L}}\right)_{20}$ with TSS in

257 the MBR compared to the CAS system (Freitas and Teixeira, 2001).

\subsection{Effect of activated sludge deflocculation on oxygen transfer: Period 2}

260 In Period 2 the amount of nitrogen and phosphorous in the synthetic influent wastewater was

261 decreased in order to simulate the effects of a nutrients unbalanced wastewater on the oxygen transfer 262 efficiency. Figure 4 depicts the relationship between the $\left(\mathrm{k}_{\mathrm{La}}\right)_{20}$ (Fig. $\left.4 \mathrm{a}\right)$ and the $\alpha$-factor (Fig. $\left.4 \mathrm{~b}\right)$ 263 with the TSS concentration in the CAS and MBR in Period 2.

a)

$\mathrm{C}: \mathrm{N}: \mathrm{P}=100: 2.5: 0.5$

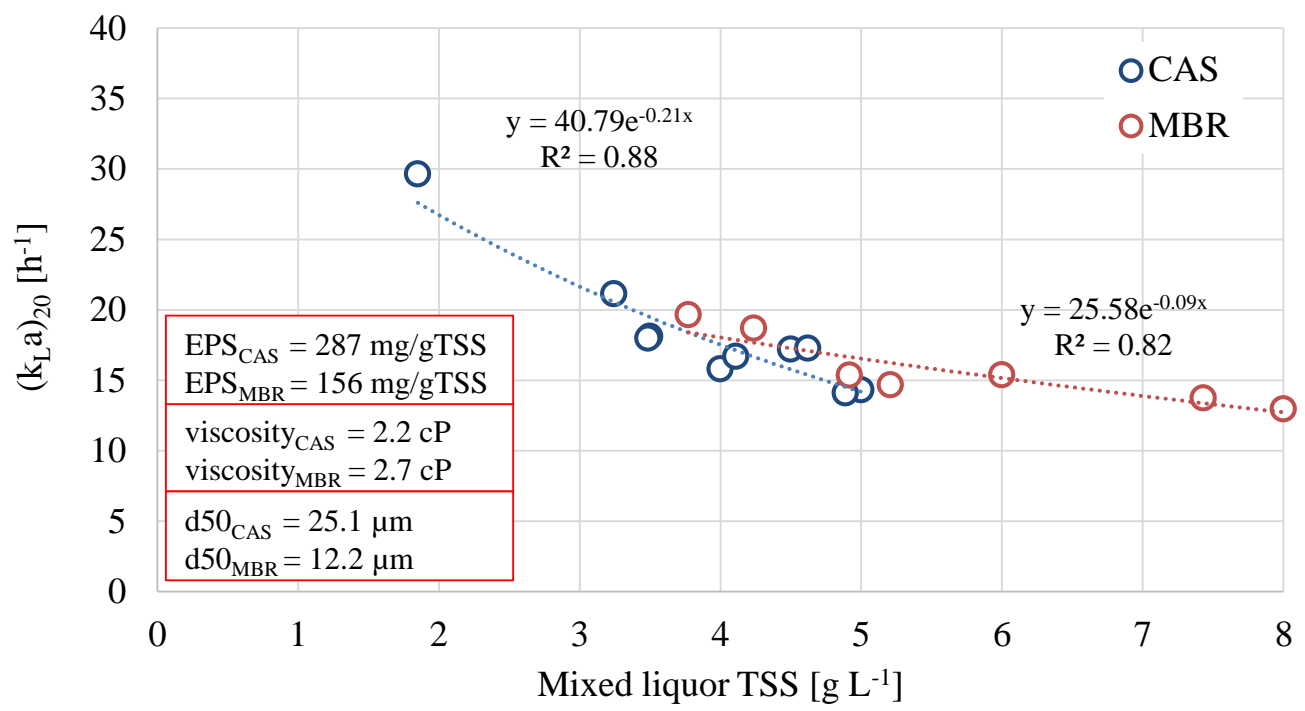

b) $\quad \mathrm{C}: \mathrm{N}: \mathrm{P}=100: 2.5: 0.5$

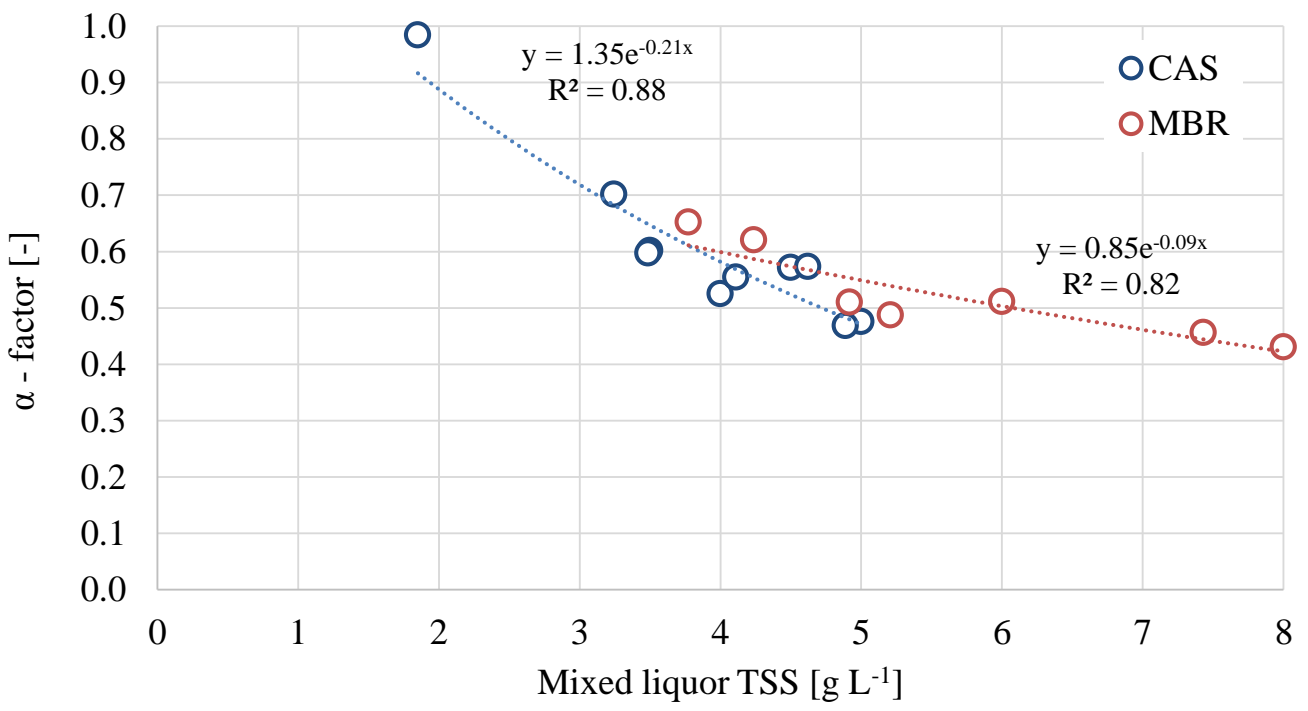


The results shown in Figure 4 indicated that $\left(\mathrm{k}_{\mathrm{L}}\right)_{20}$ increased in both CAS and MBR plants because 267 of the nutrients unbalance. Overall, a weaker dependence of $\left(\mathrm{k}_{\mathrm{La}}\right)_{20}$ with TSS was observed compared to Period 1. Indeed, although the $\left(\mathrm{k}_{\mathrm{La}}\right)_{20}$ showed the same exponential decreasing trend observed in Period 1, the $\left(\mathrm{k}_{\mathrm{L}} \mathrm{a}\right)_{20}$ values obtained in Period 2, at equal TSS concentration, significantly increased. The $\left(\mathrm{k}_{\mathrm{L}} \mathrm{a}\right)_{20}$ in the CAS decreased from $30 \mathrm{~h}^{-1}$ to less than $15 \mathrm{~h}^{-1}$ when the TSS concentration increased from 2 gTSS L ${ }^{-1}$ to 4 gTSS L ${ }^{-1}$, whereas in Period 1 it decreased to less than $5 \mathrm{~h}^{-1}$ within the same range of TSS. At higher TSS the $\left(\mathrm{k}_{\mathrm{La}}\right)_{20}$ did not decreased further, standing at a constant value of approximately $15 \mathrm{~h}^{-1}$. Similarly, the $\left(\mathrm{k}_{\mathrm{L}} \mathrm{a}\right)_{20}$ decreased from $20 \mathrm{~h}^{-1}$ to approximately $13 \mathrm{~h}^{-1}$ in the MBR when the TSS concentration increased from $4 \mathrm{~g} \mathrm{TSS} \mathrm{L}^{-1}$ to $8 \mathrm{~g} \mathrm{TSS} \mathrm{L}^{-1}$, showing a weaker dependence with TSS compared to CAS system. The $\alpha$-factor decreased from 0.97 to 0.48 when the TSS concentration increased from $2 \mathrm{~g} \mathrm{TSS} \mathrm{L}^{-1}$ to $5 \mathrm{~g} \mathrm{TSS} \mathrm{L}^{-1}$, whereas in the MBR it decreased from 0.65 to 0.42 within a range of TSS between $3.6 \mathrm{~g} \mathrm{TSS} \mathrm{L}^{-1}$ and $8 \mathrm{~g} \mathrm{TSS} \mathrm{L}^{-1}$.

Overall, the differences between the oxygen transfer in the CAS and MBR significantly reduced in Period 2. Because of the nutrients unbalance, the physical properties of the activated sludge significantly changed in both the systems. The average EPS content decreased from $311 \mathrm{mg} \mathrm{g}^{-1} \mathrm{TSS}$ to $287 \mathrm{mg} \mathrm{g}^{-1} \mathrm{TSS}$ and from $244 \mathrm{mg} \mathrm{g}^{-1} \mathrm{TSS}$ to $156 \mathrm{mg} \mathrm{g}^{-1} \mathrm{TSS}$ in the CAS and the MBR, respectively. Similarly, the size of the activated sludge flocs significantly decreased in the CAS from $91.8 \mu \mathrm{m}$ to $25.1 \mu \mathrm{m}$, indicating the occurrence of a massive deflocculation, whereas in the MBR the size of the flocs decreased to a lesser extent from $26.6 \mu \mathrm{m}$ to $12.2 \mu \mathrm{m}$. The achieved result indicated that the decrease in the EPS content and the size of activated sludge flocs significantly improved the oxygen transfer in both the systems. Moreover, both the $\left(\mathrm{k}_{\mathrm{L}} \mathrm{a}\right)_{20}$ and the $\alpha$-factor resulted very similar in both systems. Previous studies highlighted significantly poorer oxygen transfer efficiency in presence of filamentous organisms, concerning in particular to the Thiothrix eikelboomi, due to the enhancement of sludge viscosity and particular cell surface (Liu et al., 2018; Wu et al., 2019). In the present study, 
Thiothrix eikelboomi), their negative effect on oxygen transfer could be masked by the beneficial

292 variation of other parameters, such as EPS, open floc structure and average floc size.

293 A comparison of the oxygen transfer, in terms of $\left(\mathrm{k}_{\mathrm{L}} \mathrm{a}\right)_{20}$, with the TSS in Period 1 and Period 2 in the 294 CAS and MBR is depicted in Figure 5.

295

a)

CAS

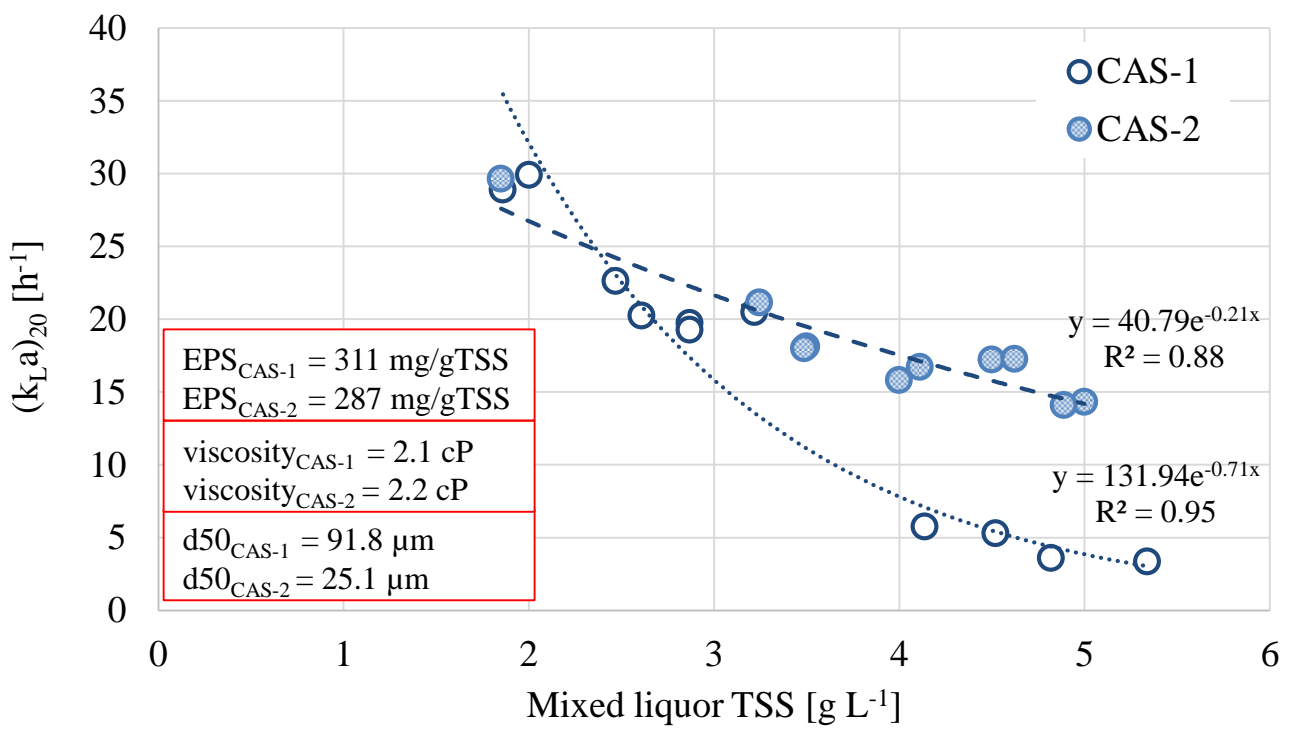

b) $\mathrm{MBR}$

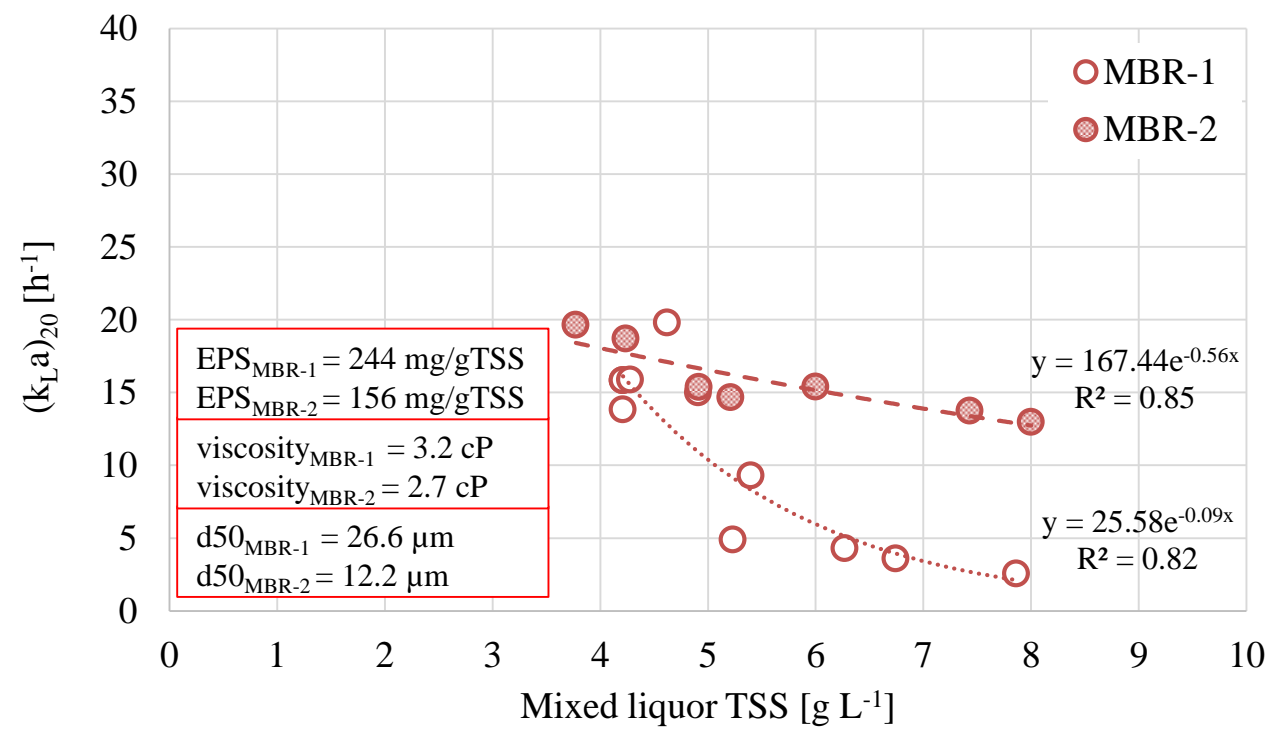

297 In the CAS, at TSS lower than $2.5 \mathrm{~g} \mathrm{TSS} \mathrm{L}^{-1}$ the $\left(\mathrm{k}_{\mathrm{L} a}\right)_{20}$ was slightly higher in Period 1, whereas at 298 higher TSS concentration the $\left(\mathrm{k}_{\mathrm{L}} \mathrm{a}\right)_{20}$ was higher in Period 2. As aforementioned, the dependence of 299 the $\left(\mathrm{k}_{\mathrm{L}} \mathrm{a}\right)_{20}$ with TSS significantly reduced in Period 2 and their relationship became almost linear. 
300 The above observations were replicable for the MBR, although the increase in the $\left(\mathrm{k}_{\mathrm{L}} \mathrm{a}\right)_{20}$ was lower 301 compared to the CAS.

302 The higher increasing trend of $\left(\mathrm{k}_{\mathrm{L}} \mathrm{a}\right)_{20}$ observed in the CAS system was likely due to the greater 303 deflocculation effect observed in this system. In view of a slight decrease in the specific EPS content $304(<10 \%)$, the only characteristic of the activated sludge flocs that significantly changed in the CAS 305 from Period 1 to Period 2 was the average size of the bioaggragates and the higher abundance of 306 filamentous bacteria. Therefore, it can be stated that the increase in the $\left(\mathrm{k}_{\mathrm{L}} \mathrm{a}\right)_{20}$ in the CAS was mainly 307 driven by the activated sludge deflocculation. In previous literature, it was observed a negative impact 308 of the filamentous overgrowth on the oxygen transfer (Liu et al., 2018). The authors noted a 309 significant worsening in the oxygen transfer efficiency due to the filamentous microorganisms that 310 caused the increase of the EPS content in the activated sludge and its viscosity. Nevertheless, the 311 authors only speculated that the filamentous overgrowth caused an increase in the activated sludge 312 viscosity, thus decreasing the oxygen transfer efficiency. In the present study, the filamentous 313 overgrowth observed mainly in the CAS during Period 2, did not cause a significant increase in the 314 activated sludge viscosity. In contrast, it modified the sludge morphology creating open-flocs 315 structure having much greater specific surface area and greater exposure to the bulk solution.

316 The effect of the decrease in the floc size was lower in the MBR, because it was smaller since the 317 beginning. Nevertheless, it was compensated by the decrease of the EPS content, close to $36 \%$. This 318 result was in good agreement with previous literature, which reported the negative impact of the bio319 surfactants like EPS in the oxygen transfer efficiency (Capodici et al., 2014).

320 Based on the above results, it can be concluded that the nutrient unbalance improved the oxygen 321 transfer in both the CAS and MBR, although the mechanisms involved in the increase in the $\left(\mathrm{k}_{\mathrm{L}} \mathrm{a}\right)_{20}$ 322 were different. 
325 The above results indicated that the decrease of the EPS content improved the oxygen transfer. In 326 light of this, with the aim to better clarify the role of the EPS compounds on the oxygen transfer 327 behavior, the $\left(\mathrm{k}_{\mathrm{L}} \mathrm{a}\right)_{20}$ was correlated with the protein $(\mathrm{PN})$ to carbohydrates $(\mathrm{PS})$ ratio (PN/PS) (Fig. 328 6).

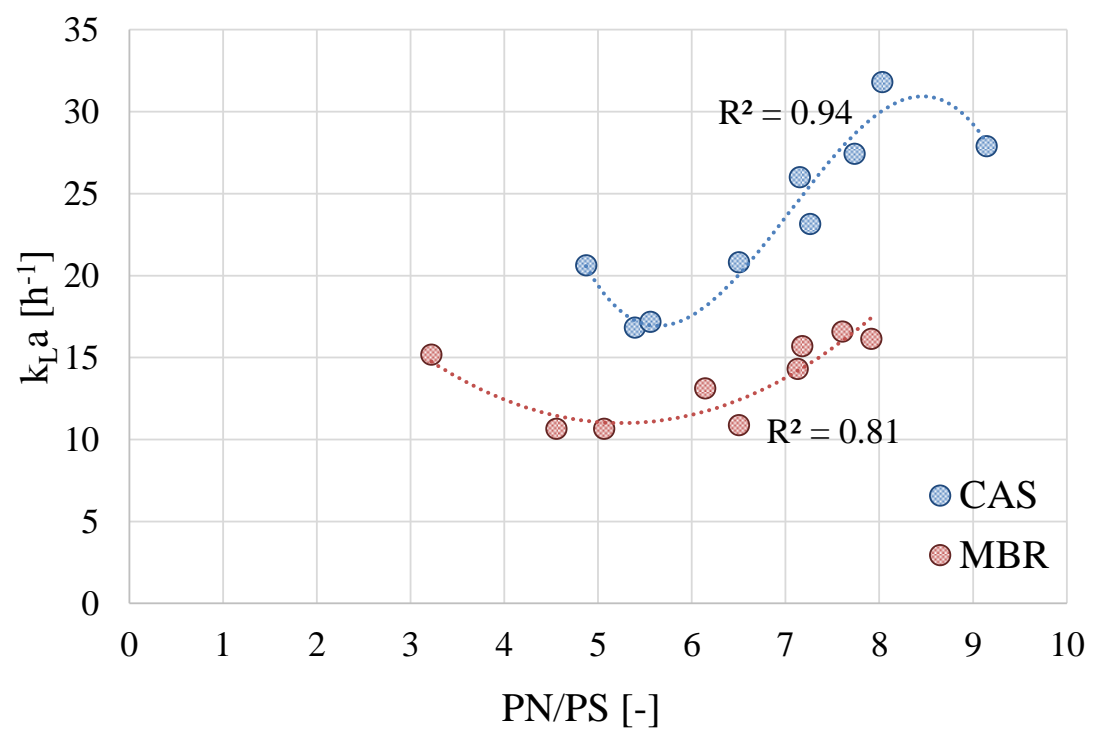

330 The $\left(\mathrm{k}_{\mathrm{L} a}\right)_{20}$ and the PN/PS showed a good correlation in both the CAS and MBR plants. More 331 precisely, the $\left(\mathrm{k}_{\mathrm{L}}\right)_{20}$ significantly increased when the PN/PS was higher than 5, showing an exponential trend in both systems. The $\left(\mathrm{k}_{\mathrm{L}} \mathrm{a}\right)_{20}$ almost doubled in the CAS when the PN/PS increased from 5 to 8, whereas in increased for approximately 50\% in the MBR. Therefore, the increase of protein in the EPS matrix was found to be favorable to oxygen transfer. This result was in contrast with previous literature (Germain et al., 2007), where the EPS component that influenced positively the oxygen transfer was found to be the carbohydrate. Germain and co-workers observed that the carbohydrates of the EPS increased flocs porosity and therefore the oxygen diffusivity. In the present study, the highest PN/PS was observed in Period 2 in both systems, when, because of the filamentous overgrowth and the deflocculation, the floc porosity likely increased independently of EPS composition. As previously discussed, the abundance of filamentous bacteria in Period 2 caused the change in the activated sludge morphology to open-flocs structure that was likely favorable to oxygen transfer. Besides, it is worth mentioning that the prevalence of the proteins over the carbohydrates in the EPS matrix increased the sludge hydrophobicity, because of the hydrophobic nature of the 
344 proteinaceous molecules (Ras et al., 2013). Given the hydrophobic nature of the air bubbles (Shi et 345 al., 2014), it is possible to speculate that the increase in the proteinaceous fraction of the EPS matrix, 346 improved the oxygen transfer because of the establishment of hydrophobic interaction between the 347 activated sludge flocs enriched in proteins and the air bubbles (Ferreira et al., 2010; Mena et al., 348 2011). Therefore, the in $\left(\mathrm{k}_{\mathrm{L}} \mathrm{a}\right)_{20}$ in addition to TSS, EPS content and floc size, was found to be 349 dependent of the protein content of the extracellular polymeric matrix.

\subsection{Relative influence of the biomass features on $\left(k_{L} a\right)_{20}$}

352 Based on the above considerations, the main features of activated sludge that affected the $\left(\mathrm{k}_{\mathrm{L} a}\right)_{20}$ were 353 the TSS, the total EPS content, the PN/PS, the sludge viscosity and the average size of the flocs. In 354 order to evaluate their degree of influence on the oxygen transfer coefficient, a multiple regression 355 analysis was carried out considering the values of $\left(\mathrm{k}_{\mathrm{L}} \mathrm{a}\right)_{20}$ obtained during the entire experiment. The 356 beta coefficients and the statistical significance parameters obtained by the regression analysis are reported in Table 2.

\begin{tabular}{lcc}
\hline Parameter & CAS & MBR \\
\hline TSS & -4.48 & -3.01 \\
EPS & -0.86 & -0.50 \\
PN/PS & 0.68 & 0.98 \\
Viscosity & -1.03 & -1.75 \\
Flocs size & -1.62 & -2.37 \\
F & 31.6 & 14.5 \\
p-level & $<0.05$ & $<0.05$ \\
\hline
\end{tabular}

360 The obtained results indicated that the degree of influence of the investigated parameters for both the 361 systems were in order: the TSS concentration, flocs size, viscosity, PN/PS and EPS content. More 362 precisely, the TSS, the EPS, the viscosity and the flocs size had a negative influence, meaning that an 363 increase in these parameter led to a decrease of the $\left(\mathrm{k}_{\mathrm{L} a}\right)_{20}$, whereas the only parameter having a positive influence was the PN/PS. As afore discussed, the TSS concentration had a higher influence 
on $\left(\mathrm{k}_{\mathrm{La}}\right)_{20}$ in the CAS than the MBR, as well as the EPS. In contrast, the activated sludge viscosity,

366 the flocs size and the PN/PS had a greater influence in the MBR.

367 Based on the typical operating conditions of CAS and MBR systems, the activated sludge viscosity 368 is generally higher in the MBR, because of the higher TSS concentration they operate (Germain et 369 al., 2007), as well as the average size of the flocs is significantly lower in the MBR (Campo et al., 370 2017). Moreover, because of the higher sludge retention time and the lower F/M, the amount of EPS 371 is lower, whereas that of proteins in relation to carbohydrates in the EPS matrix is higher in the MBR. 372 Indeed, endogenous metabolic condition imposed by the low F/M, are reported to produce a selective 373 enrichment of proteins in the EPS, due to the biodegradation of the carbohydrates that from a 374 molecular point of view are structurally more simple than proteins (Duan et al., 2014). In contrast, in 375 CAS systems, although the TSS concentration is lower, the amount of EPS is higher than MBR 376 because of the higher F/M.

377 Based on the afore discussed degrees of influence of the main biomass features affecting the $\left(k_{L} a\right)_{20}$, 378 the operating conditions in MBR systems and its activated sludge features, appeared to be more 379 favorable to oxygen transfer efficiency compared to CAS systems. Nevertheless, an excessive 380 deviation of the above reported parameters from the ranges investigated in the present study could 381 led to different results because of the increase of the degree of influence of such parameter on the oxygen transfer efficiency.

\section{Conclusions}

385 A comparison between the oxygen transfer efficiency in CAS and MBR was performed in the present study. The $\left(\mathrm{k}_{\mathrm{L}}\right)_{20}$ and $\alpha$-factor showed exponential decreasing trends with TSS in the CAS and MBR, even if it was noted that the dependence of both parameters on TSS was stronger in the CAS than the MBR. Although under the typical operating conditions in terms of TSS concentration in the CAS and MBR the oxygen transfer coefficient was lower in the MBR $\left(3.6 \mathrm{~h}^{-1} \mathrm{vs} 20 \mathrm{~h}^{-1}\right)$, it was noted that the 
391 The achieved results indicated that under similar operating conditions the features of the activated 392 sludge flocs in the MBR were more favorable to oxygen diffusion process because of the smaller 393 particle size.

394 Moreover, the results indicated that the TSS, the EPS, the viscosity and the flocs size had a negative 395 influence on the $\left(\mathrm{k}_{\mathrm{L}} \mathrm{a}\right)_{20}$, whereas the only parameter having a positive influence was the PN/PS. The 396 TSS concentration had a greater influence on $\left(\mathrm{k}_{\mathrm{L} a}\right)_{20}$ in the CAS than the MBR, as well as the EPS. 397 In contrast, the activated sludge viscosity, the flocs size and the PN/PS had a greater influence in the 398 MBR.

399 Based on the degrees of influence of the main biomass features affecting the $\left(\mathrm{k}_{\mathrm{L}} \mathrm{a}\right)_{20}$ and considering 400 the typical operating conditions in both systems, those of the MBR appeared to be more favorable to 401 oxygen transfer efficiency compared to CAS.

\section{References}

404 Bertanza, G., Canato, M., Laera, G., Vaccari, M., Svanström, M., Heimersson, S., 2017. A 405 comparison between two full-scale MBR and CAS municipal wastewater treatment plants:

Campo, R., Capodici, M., Di Bella, G., Torregrossa, M., 2017. The role of EPS in the foaming and techno-economic-environmental assessment. Environ. Sci. Pollut. Res. 24, 17383-17393. doi:10.1007/s11356-017-9409-3

411 Capodici, M., Di Bella, G., Nicosia, S., Torregrossa, M., 2014. Effect of chemical and biological surfactants on activated sludge of MBR system: Microscopic analysis and foam test. Bioresour.

Di Bella, G., Durante, F., Torregrossa, M., Viviani, G., 2010. Start-up with or without inoculum? Analysis of an SMBR pilot plant. Desalination 260, 79-90. doi:10.1016/j.desal.2010.04.063 
Duan, L., Song, Y., Yu, H., Xia, S., Hermanowicz, S.W., 2014. The effect of solids retention times on the characterization of extracellular polymeric substances and soluble microbial products in a submerged membrane bioreactor. Bioresour. Technol. 163, 395-398. doi:10.1016/j.biortech.2014.04.112

DuBois, M., Gilles, K. a., Hamilton, J.K., Rebers, P. a., Smith, F., 1956. Colorimetric method for determination of sugars and related substances. Anal. Chem. 28, 350-356. doi:10.1021/ac60111a017

Fan, H., Liu, X., Wang, H., Han, Y., Qi, L., Wang, H., 2017. Oxygen transfer dynamics and activated sludge floc structure under different sludge retention times at low dissolved oxygen concentrations. Chemosphere. doi:10.1016/j.chemosphere.2016.10.137

Ferreira, A., Ferreira, C., Teixeira, J.A., Rocha, F., 2010. Temperature and solid properties effects on gas-liquid mass transfer. Chem. Eng. J. 162, 743-752. doi:10.1016/j.cej.2010.05.064

Freitas, C., Teixeira, J.A., 2001. Oxygen mass transfer in a high solids loading three-phase internalloop airlift reactor. Chem. Eng. J. 84, 57-61. doi:10.1016/S1385-8947(00)00274-6

Germain, E., Nelles, F., Drews, A., Pearce, P., Kraume, M., Reid, E., Judd, S.J., Stephenson, T., 2007. Biomass effects on oxygen transfer in membrane bioreactors. Water Res. 41, 1038-1044. doi:10.1016/j.watres.2006.10.020

Germain, E., Stephenson, T., 2005. Biomass characteristics, aeration and oxygen transfer in membrane bioreactors: Their interrelations explained by a review of aerobic biological processes. Rev. Environ. Sci. Biotechnol. doi:10.1007/s11157-005-2097-3 treatment plants. J. Clean. Prod. 142, 323-330. doi.org/10.1016/j.jclepro.2016.03.173. 
Le-Clech, P., Chen, V., Fane, T.A.G., 2006. Fouling in membrane bioreactors used in wastewater treatment. J. Memb. Sci. doi:10.1016/j.memsci.2006.08.019

Li, W., Li, L., Qiu, G., 2017. Energy consumption and economic cost of typical wastewater treatment systems in Shenzhen, China. J. Clean. Prod. 163, S374-S378. doi.org/10.1016/j.jclepro.2015.12.109

Liu, G., Wang, J., Campbell, K., 2018. Formation of filamentous microorganisms impedes oxygen transfer and decreases aeration efficiency for wastewater treatment. J. Clean. Prod. 189, 502509. doi:10.1016/j.jclepro.2018.04.125

Lowry, O.H., Rosebrough, N.J., Farr, A.L., Randall, R.J., 1951. Protein measurement with the FolinPhenol Reagent. J. Biol. Cemistry 193, 265-275. 
Mena, P., Ferreira, A., Teixeira, J.A., Rocha, F., 2011. Effect of some solid properties on gas-liquid mass transfer in a bubble column. Chem. Eng. Process. Process Intensif. 50, 181-188. doi:10.1016/j.cep.2010.12.013

Mueller, J.A., Boyle, W.C., Popel, H.J., 2002. Aeration: Principles and Practice. CRC Press. Boca Raton, USA.

Ras, M., Lefebvre, D., Derlon, N., Hamelin, J., Bernet, N., Paul, E., Girbal-Neuhauser, E., 2013. Distribution and hydrophobic properties of Extracellular Polymeric Substances in biofilms in relation towards cohesion. J. Biotechnol. 165, 85-92. doi:10.1016/j.jbiotec.2013.03.001

Rosso, D., Larson, L.E., Stenstrom, M.K., 2008. Aeration of large-scale municipal wastewater treatment plants: State of the art. Water Sci. Technol. doi:10.2166/wst.2008.218

Shi, C., Chan, D.Y.C., Liu, Q., Zeng, H., 2014. Probing the hydrophobic interaction between air bubbles and partially hydrophobic surfaces using atomic force microscopy. J. Phys. Chem. C 118, 25000-25008. doi:10.1021/jp507164c

Stenstrom, M.K., Leu, S.-Y. (Ben), Jiang, P., 2006. Theory to Practice: Oxygen Transfer and the New ASCE Standard. Proc. Water Environ. Fed. 2006, 4838-4852. doi:10.2175/193864706783762931

Thang, B., Qiu, B., Huang, S., Yang, K., Bin, L., Fu, F., Yang, H. 2015. Distribution and mass transfer of dissolved oxygen in a multi-habitat membrane bioreactor. Bioresour. Technol. 182, 323-328. doi.org/10.1016/j.biortech.2015.02.028

Torregrossa, D., Hernández-Sancho, F., Hansen, J., Cornelissen, A., Popov, T., Schutz, G., 2018. Energy saving in wastewater treatment plants: A plant-generic cooperative decision support system. J. Clean. Prod. 167, 601-609. doi:10.1016/j.jclepro.2017.08.181 
482 Verrecht, B., Maere, T., Nopens, I., Brepols, C., Judd, S. 2010. The cost of a large-scale hollow fibre 483 MBR, Water Res. 44, 5274-5283. doi:10.1016/j.watres.2010.06.054.

484 Wu., X., Huang, J., Lu, Z., Chen, G., Wang, J., Liu, G. 2019. Thiothrix eikelboomii interferes oxygen 485 transfer in activated sludge. Water Res. 151, 134-143. doi.org/10.1016/j.watres.2018.12.01

486 Xu, Y., Zhu, N., Sun, J., Liang, P., Xiao, K., Huang, X. 2017. Evaluating oxygen mass transfer 487 parameters for large-scale engineering application of membrane bioreactors. Proc. Biochem. 60, $488 \quad$ 13-18. doi.org/10.1016/j.procbio.2017.05.020

489 Zheng, Z., Sun, D., Li, J., Zhan, X., Gao, M., 2018. Improving oxygen transfer efficiency by 490 developing a novel energy-saving impeller. Chem. Eng. Res. Des. 130, 199-207. $491 \quad$ doi:10.1016/j.cherd.2017.12.021 
$495 \quad$ Figure 1: Layout of the CAS and MBR

496 Figure 2: Average EPS content, composition, and activated sludge viscosity (a), microscopic 497 observation of the sludge in the CAS and MBR during Period 1 and Period 2.

$498 \quad$ Figure 3: Oxygen transfer coefficient (a) and $\alpha$-factor $v s$ TSS in CAS and MBR in Period 1

499 Figure 4: Oxygen transfer coefficient (a) and $\alpha$-factor $v s$ TSS in CAS and MBR in Period 2

500 Figure 5: Comparison between the $\left(\mathrm{k}_{\mathrm{L}} \mathrm{a}\right)_{20}$ in Period 1 and Period 2 in the CAS (a) and MBR (b).

501 Figure 6: Relationship between the $\left(\mathrm{k}_{\mathrm{L}}\right)_{20}$ and the PN/PS ratio of the EPS in the CAS and MBR

TABLE LEGENDS

507 Table 1: Features of the synthetic wastewater

508 Table 2: Beta coefficients and statistical significance parameters obtained by regression analysis for $509 \quad\left(k_{\mathrm{L}} \mathrm{a}\right)_{20}$ 